\title{
IMPACT OF MANUFACTURING TOLERANCES ON STRESS IN A TURBINE BLADE FIR-TREE ROOT
}

\author{
Grzegorz Moneta ${ }^{1 *}$ • ORCID: 0000-0003-3899-1957 \\ Jerzy Jachimowicz ${ }^{2}$ ORCID: 0000-0002-0486-6448 \\ ${ }^{1}$ Łukasiewicz Research Network - Institute of Aviation, \\ A1. Krakowska 110/114, 02-256 Warsaw, Poland \\ ${ }^{2}$ Military University of Technology, Sylwestra Kaliskiego Str. 2, 00-908 Warsaw \\ *grzegorz.moneta@ilot.lukasiewicz.gov.pl
}

\begin{abstract}
Low Cycle Fatigue (LCF) is one of most common mechanisms behind turbine blade failures. The reason is high stress concentration in notch areas, like fir-tree root groves, which can cause cyclic stress beyond the safe threshold. The stress levels strictly depend on the manufacturing accuracy of the fir-tree lock (for both fitted together: blade root and disk groove). The probabilistic study aimed at determination of stress was performed using Finite Element Method (FEM) simulation on a population of 1000 turbine models (disk + blades +friction dampers), where fir-tree lock dimensions were sampled according to the normal distribution, within limits specified in the documentation. The studies were performed for different manufacturing quality levels: 3-Sigma, 6-Sigma and 3-Sigma with tolerance ranges reduced twice. Based on the results, the probabilistic distributions, probabilities and expected ranges of values could be determined for: material plastification, stress, strain, LCF lifetime, etc. The study has shown how each tooth of the root is loaded and how wide a stress range should be expected in each groove. That gives information on how the definition of tolerances should be modified to make the construction more optimal, more robust, with lower likelihood of damage, taking into account the cost-quality balance. It also shows how the Six Sigma philosophy can improve the safety of the construction, its repeatability and predictability. Additionally, the presented numerical study is a few orders of magnitude more cost- and time-effective than experiment.
\end{abstract}

Keywords: fir-tree root, turbine, lock, blade, disk, manufacturing tolerances, Monte-Carlo simulations, Six Sigma, Low Cycle Fatigue, Design of Experiment Article Category: Research Article 


\section{INTRODUCTION}

When Frank Whittle was building the first jet engine in 1941, he faced with the problem of blade fatigue failures. He believed that the frequency of turbine blade failures was last technological barrier to overcome [10]. Even till today, one of the most important issues in turbine design is elimination of stress concentrations, especially in blade-disk locks.

Fig. 1 shows a turbine disc with fatigue cracks due to turbine blades vibrations. That is the effect of: stress concentrations in the grooves, uneven teeth loading caused by manufacturing tolerances (Fig. 1b) and cyclic load [4, 6].

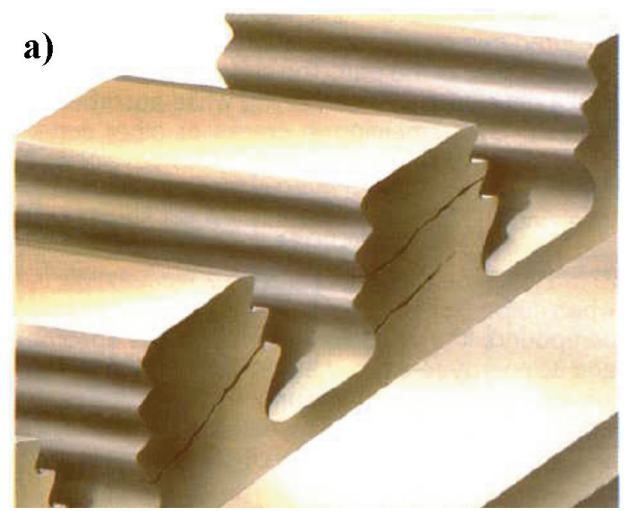

b)

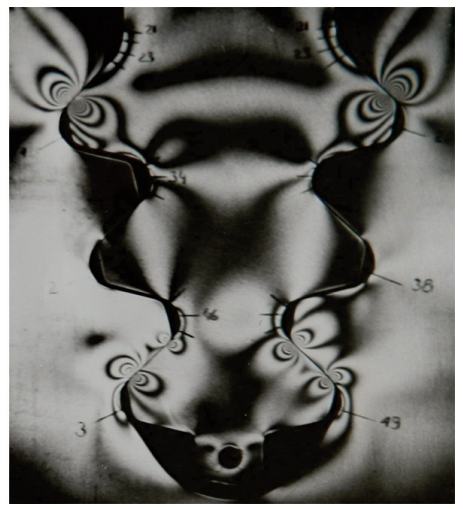

Fig. 1. Fatigue cracks in the fir-tree attachment of the disk [11] (a) and elasto-optic stress distribution [4] (b).

The common practice employed to reduce stress concentrations in turbine design is shape optimization [12]. An additional issue is the repeatability of manufacturing of parts - tolerances. The experience shows that sometimes designers observe a fatigue failure of one blade-groove pair in a set. This is due to differences in shape, material properties, boundary conditions etc. Usually, the range of extreme possible stress is assessed taking into consideration extreme tolerances and ranges of other parameters. Another method is the probabilistic approach involving determination of probabilistic distributions functions (PDF) of stress, considering distributions of all important variables. Based on that, it is possible to determine the risk of plastification, useful for estimation of engine life and probability of failure [1,3].

Conventionally, the Finite Element Method (FEM) is used during design process for static and dynamic analyses of turbine components [2,5]. Parametric models allow for simulations of thousands of variants in a very short time.

\section{TOLERANCES OF MANUFACTURING}

A very important issue encountered during the turbine blade design is low-sensitive solutions to design variables. Possible deviations should have the lowest possible influence on critical parameters, especially on stress concentration factors. However, the accuracy of manufacturing is limited by technological barriers and manufacturing costs. An example geometry of a turbine blade fir-tree root is shown in Fig. 2. 


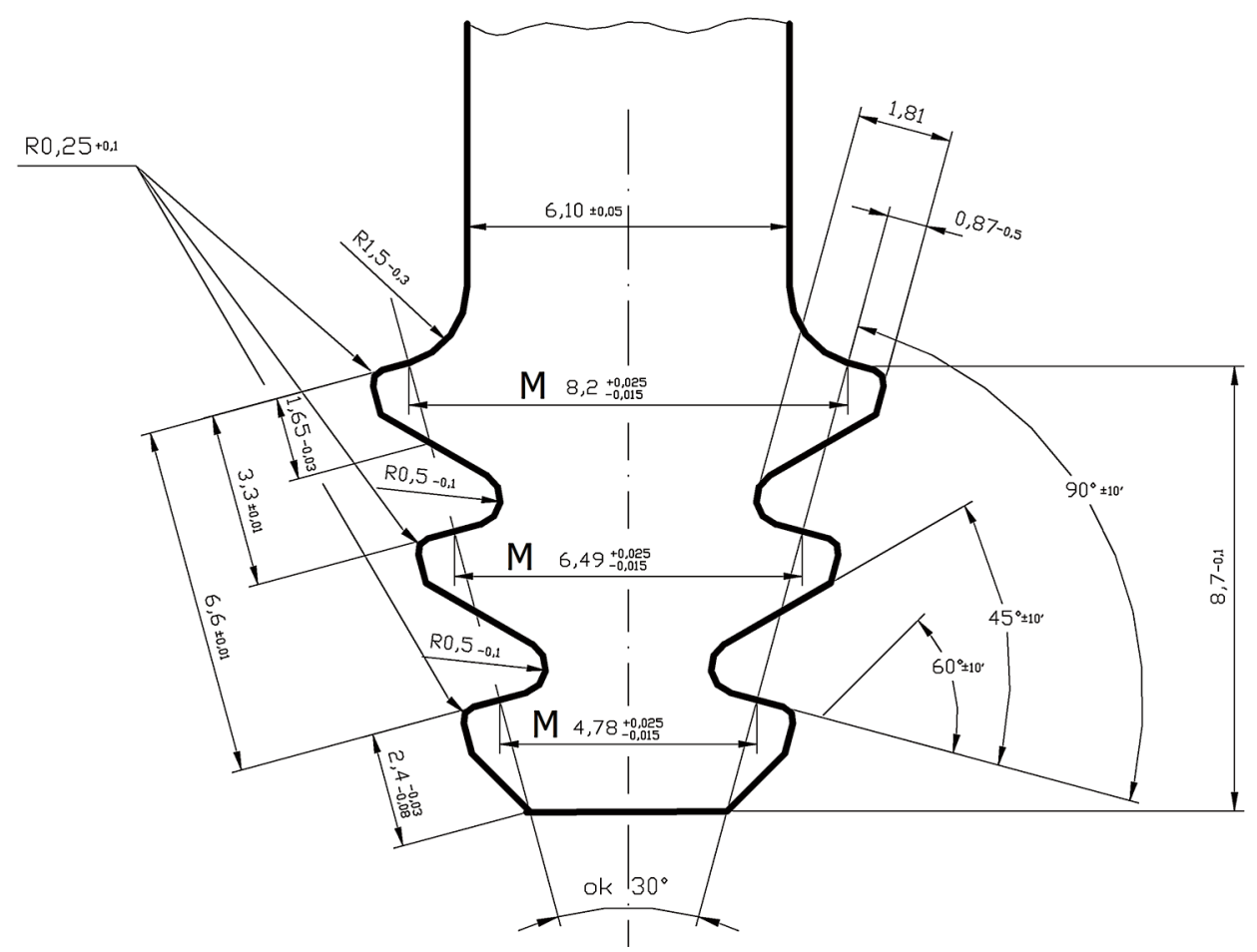

Fig. 2. Dimensions of blade fir-tree root.

Stress distribution in the nominal fir-tree lock is assessed using FEM during design process. The next step is determination of extreme possible stress values considering the worst tolerance combination sets (usually combinations of minimum and maximum values). Unfortunately, that method does not consider two important issues:

- Cases of extreme dimensions are not always able to determine possible extreme stress values for locks within manufacturing tolerances - it could be also combinations of minimum and maximum values of selected dimensions. It is possible to analyze influences of all variables separately and in the next step to create the sensitivity matrix. For real cases, the linear combination of influences of selected parameters can be used.

- Real dimensions of parts are usually characterized by probabilistic distributions (constrained by tolerances). The average value is the one most likely to be achieved while the standard deviation depends on the repeatability of the manufacturing technology (the second parameter can be estimated for example using percentage of scraped parts - e.g. 3-Sigma or 6-Sigma process).

Taking into account distributions of variables, it is possible to create a numerical experiment (e.g. Monte-Carlo simulations) for a numerous set of blades differing in: dimensions, material properties, boundary conditions etc. All variables will be sampled according to probabilistic distributions [9]. Following simulations, the analysis of results will be done (for frequencies, stresses, displacements etc.) and probabilistic distributions of output parameters will be determined. The next step is the risk assessment, for example of resonance or plasticization. 


\section{DESCRIPTION OF THE ANALYSIS}

The analysis required preparing 3D FE turbine models. The dimensions of the firtree lock (164 items in total) were parameterized and probabilistic distributions were determined for:

a. origin tolerance range and 3-Sigma manufacturing process,

b. origin tolerance range and 6-Sigma manufacturing process,

c. narrow tolerance range (50\% of reduction) and 3-Sigma manufacturing process.

Sets of 1000 turbine models were created for each of three cases, where dimensions of fir-tree were sampled according to probabilistic distributions. Temperature dependent elastic material models were used (Fig. 3.).

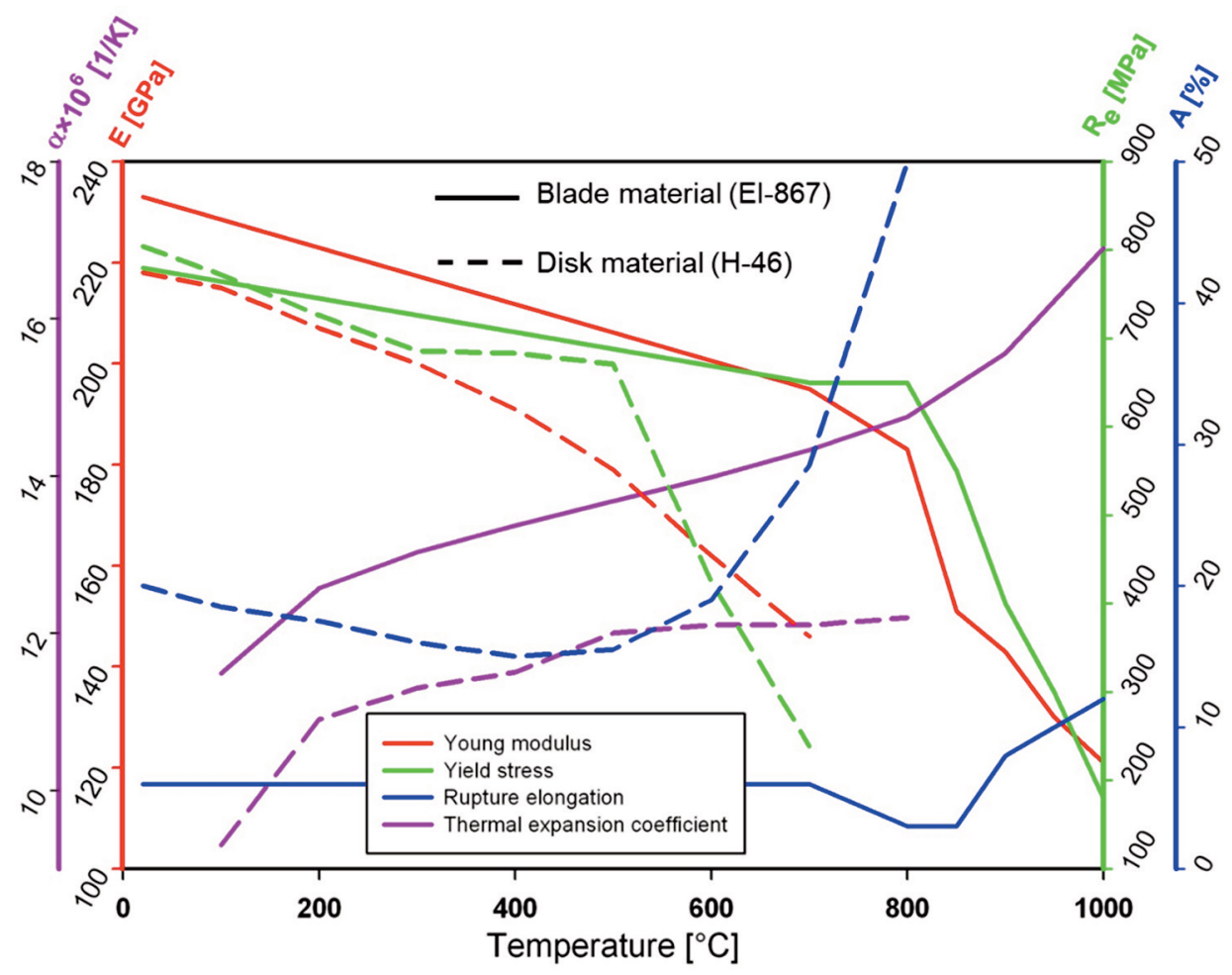

Fig. 3. Temperature-dependent material properties of turbine components.

Boundary conditions were applied in accordance with the conditions of full load: centrifugal, thermal (Fig. 4.) and gas loads. To reduce simulation time, the cyclic symmetry reduction was used.

Fig. 5 shows stress distribution of turbine components for nominal geometries and full-load condition. The next step was the determination of probabilistic distribution stress values in the grooves of the fir-tree lock. 


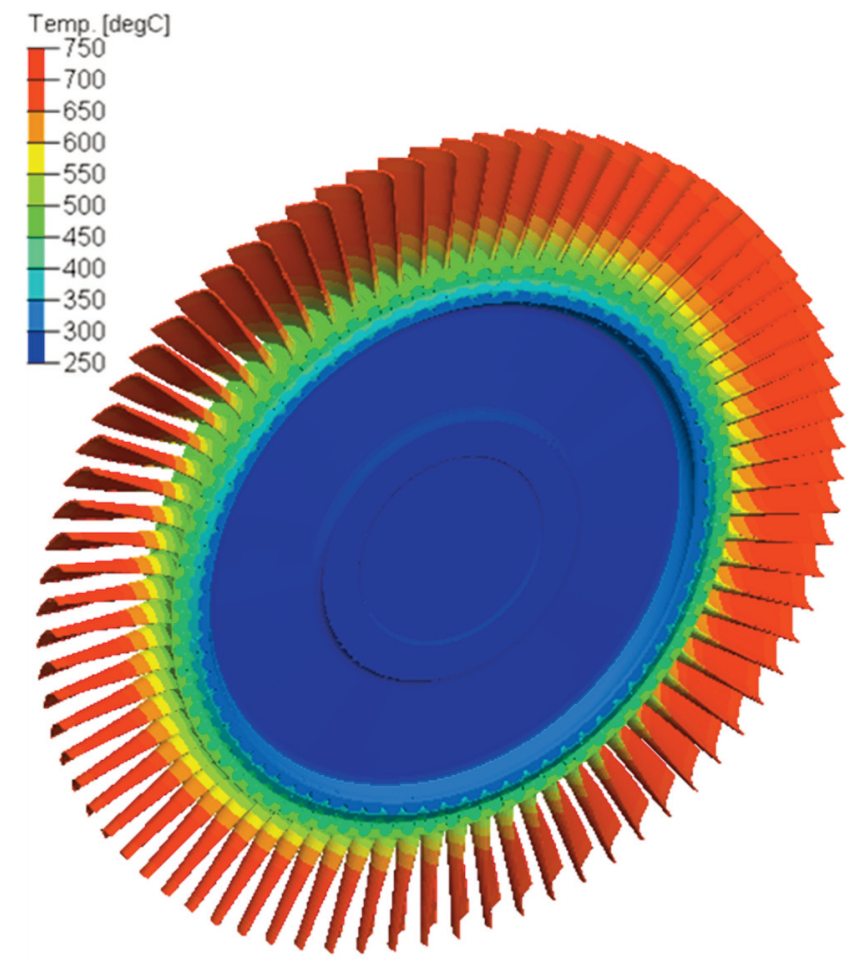

Fig. 4. Steady-state temperature distribution in turbine.
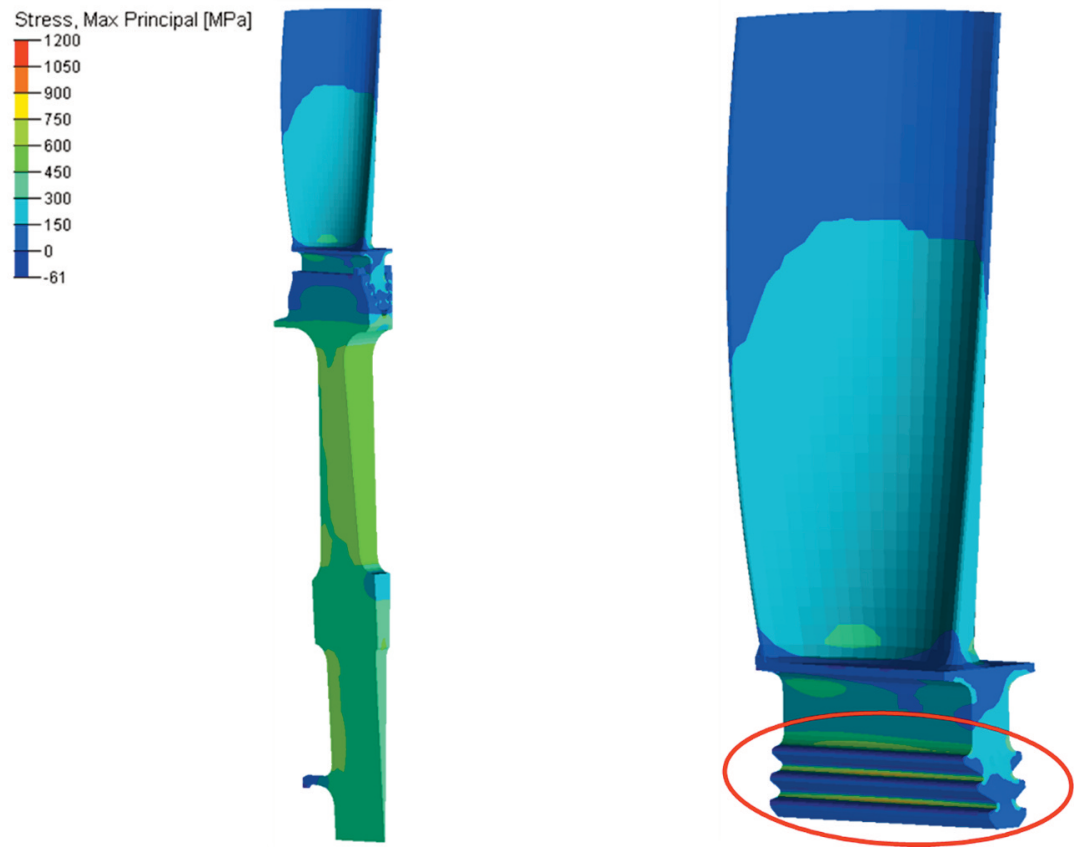

Fig. 5. Stress distribution of turbine components for full-load conditions. 


\section{RESULTS OF THE NUMERICAL EXPERIMENT}

The results of Monte-Carlo simulations are presented below. The naming convention used for selected grooves is shown in Fig. 6. For each simulation, maximum peak stress values were extracted from each groove of the fir-tree lock.
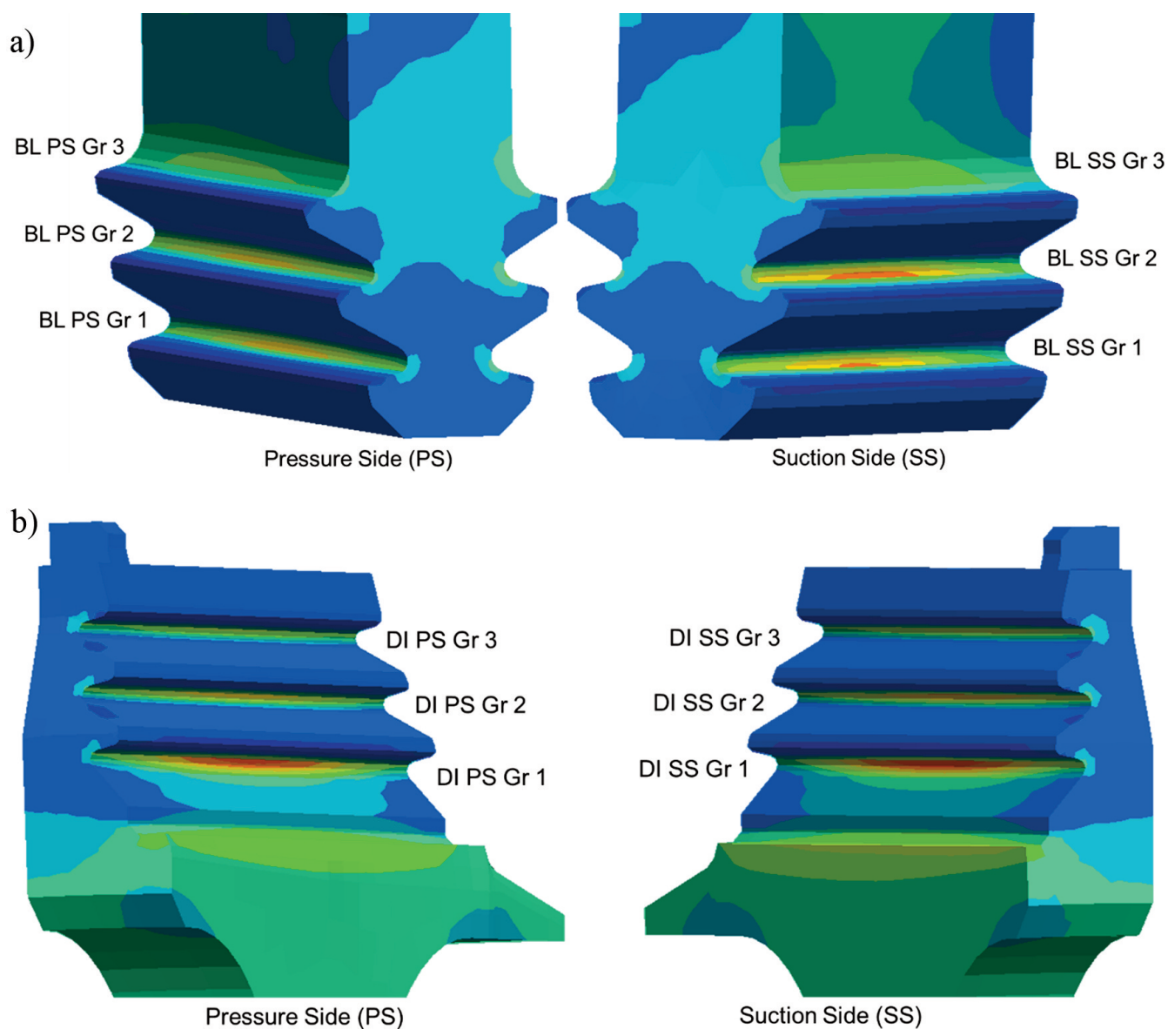

Fig. 6. Naming convention used for grooves of: blade (a) and disk (b).

The histograms and probabilistic distributions of peak stress values were prepared (Fig. 7.). Most grooves showed plastification resulting in lower LCF lifetime. The computations performed revealed that the loading of the grooves was not balanced (Grooves 1 and 2 were overloaded, while Groove 3 was underloaded). Also, the suction side teeth showed overloading compared to those on the pressure side. A better balancing of the aerofoil and optimization of the root tolerance ranges would make peak stresses of all grooves more uniform. Implementing the 6-Sigma manufacturing quality instead of the 3-Sigma one gave the effect comparable to the reduction of tolerance ranges by $50 \%$. Additionally, the repeatability and predictability of stress values were improved. Since linear-elastic material models were used for Monte-Carlo simulations, the observed stress reached values highly above the yield limits of the component materials. In future work, elasto-plastic material models will be used and probabilistic distributions of LCF lifetime will be calculated. 

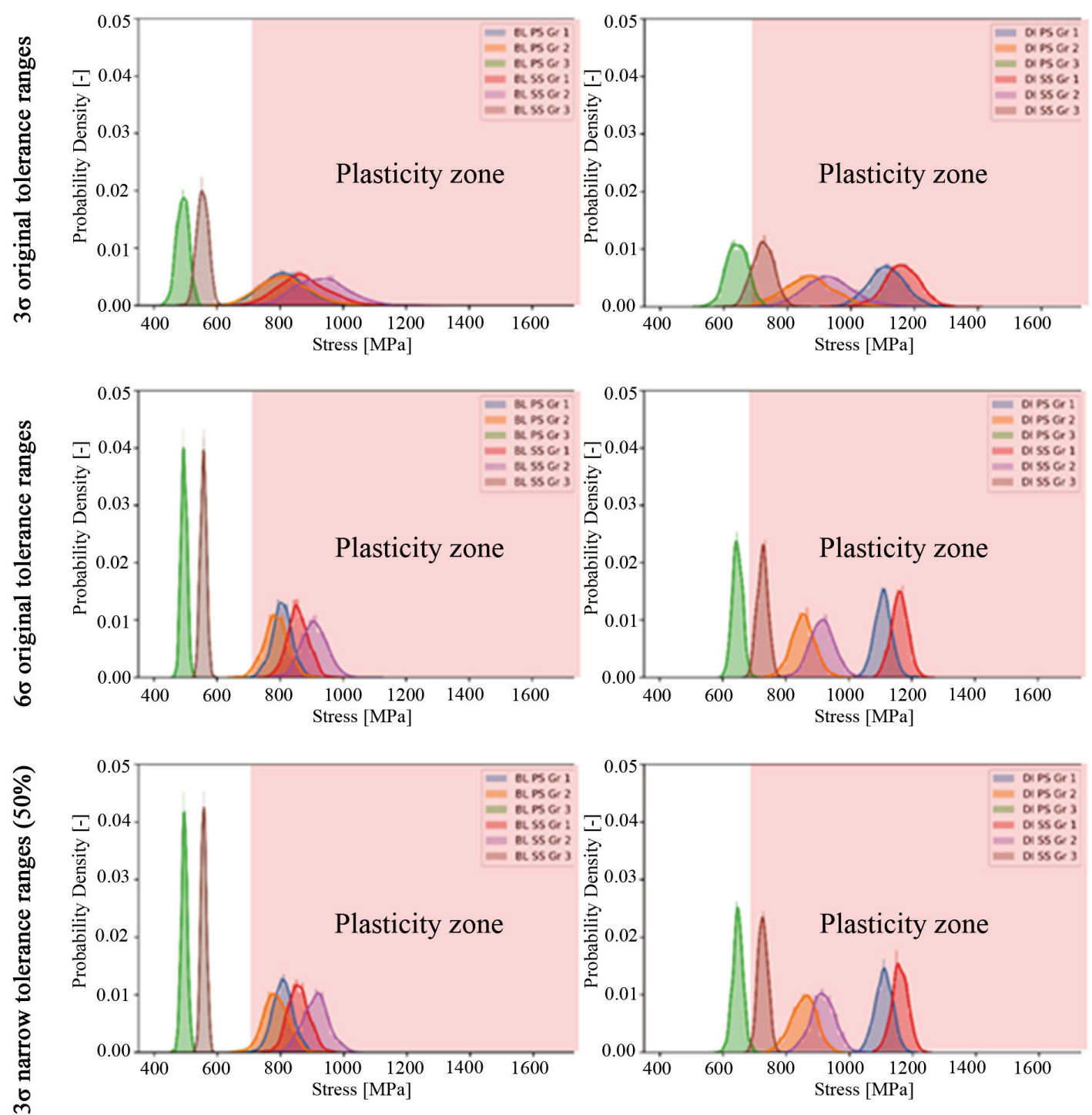

Fig. 7. Probabilistic distributions of groove peak stresses

for considered manufacturing qualities: $3 \sigma, 6 \sigma$ and $3 \sigma$ with narrow tolerances (pink color shows plasticity zones).

Statistical and probabilistic results of groove stress are presented in Tab. 1. and Tab. 2. Mean values and standard deviations were calculated for each groove and compared against each other. The fir-tree roots with narrow tolerance ranges and for 6-Sigma are characterized by about two times lower dispersions of stress (standard deviations) than locks manufactured with 3-Sigma quality. Probabilities of plastifications were calculated form Cumulative Distributions Functions (CDF) based on the yield stress limits of the materials $(703[\mathrm{MPa}]$ for the blade material and $679[\mathrm{MPa}]$ for the disk material, respectively). The likelihood of plastification of Grooves 1 and 2 is highly above $90 \%$ for both the blade and the disk. Whereas the plastification risk of Groove 3 is negligible for the blades, it is significant for disk Groove 3 (12.8\% on the pressure side and $90.6 \%$ on the suction side). 
Tab. 1. Stress results for blade grooves.

\begin{tabular}{|c|c|c|c|c|c|c|c|c|c|}
\hline \multirow{2}{*}{$\begin{array}{c}\text { Blade } \\
\text { grooves }\end{array}$} & \multicolumn{3}{|c|}{$\begin{array}{c}3 \sigma \text { original tolerance } \\
\text { ranges }\end{array}$} & \multicolumn{3}{|c|}{$\begin{array}{c}6 \sigma \text { original tolerance } \\
\text { ranges }\end{array}$} & \multicolumn{3}{|c|}{$\begin{array}{c}3 \sigma \text { narrow tolerance } \\
\text { ranges }(50 \% \text { reduction) }\end{array}$} \\
\hline & $\begin{array}{l}\text { Mean } \\
\text { stress } \\
{[\text { MPa] }}\end{array}$ & $\begin{array}{l}\text { St. dev. } \\
{[\mathrm{MPa}]}\end{array}$ & $\begin{array}{c}\text { Prob. of } \\
\text { plastif. } \\
{[\%]}\end{array}$ & $\begin{array}{l}\text { Mean } \\
\text { stress } \\
\text { [MPa] }\end{array}$ & $\begin{array}{l}\text { St. dev. } \\
{[\mathrm{MPa}]}\end{array}$ & $\begin{array}{c}\text { Prob. of } \\
\text { plastif. } \\
{[\%]}\end{array}$ & $\begin{array}{l}\text { Mean } \\
\text { stress } \\
{[\text { MPa] }}\end{array}$ & $\begin{array}{l}\text { St. dev. } \\
{[\mathrm{MPa}]}\end{array}$ & $\begin{array}{c}\text { Prob. of } \\
\text { plastif. } \\
\text { [\%] }\end{array}$ \\
\hline $\begin{array}{c}\text { BL PS } \\
\text { Gr1 }\end{array}$ & 811.7 & 70.7 & 93.697 & 806.6 & 31.1 & 99.955 & 807.0 & 31.3 & 99.953 \\
\hline $\begin{array}{l}\text { BL PS } \\
\text { Gr2 }\end{array}$ & 813.1 & 78.3 & 91.911 & 786.2 & 37.3 & 98.658 & 784.9 & 38.8 & 98.195 \\
\hline $\begin{array}{l}\text { BL PS } \\
\text { Gr3 }\end{array}$ & 490.7 & 19.4 & 0.000 & 495.2 & 9.8 & 0.000 & 495.2 & 9.8 & 0.000 \\
\hline $\begin{array}{l}\text { BL SS } \\
\text { Gr1 }\end{array}$ & 872.2 & 78.3 & 98.440 & 856.8 & 33.0 & 100.000 & 856.8 & 33.5 & 100.000 \\
\hline $\begin{array}{l}\text { BL SS } \\
\text { Gr2 }\end{array}$ & 932.1 & 80.1 & 99.784 & 908.4 & 40.5 & 100.000 & 911.7 & 39.7 & 100.000 \\
\hline $\begin{array}{c}\text { BL SS } \\
\text { Gr3 }\end{array}$ & 554.1 & 18.6 & 0.000 & 556.7 & 9.9 & 0.000 & 556.5 & 9.0 & 0.000 \\
\hline
\end{tabular}

Tab. 2. Stress results for disk grooves.

\begin{tabular}{|c|c|c|c|c|c|c|c|c|c|}
\hline \multirow[b]{2}{*}{$\begin{array}{c}\text { Disk } \\
\text { grooves }\end{array}$} & \multicolumn{3}{|c|}{$\begin{array}{c}3 \sigma \text { original tolerance } \\
\text { ranges }\end{array}$} & \multicolumn{3}{|c|}{$\begin{array}{c}6 \sigma \text { original tolerance } \\
\text { ranges }\end{array}$} & \multicolumn{3}{|c|}{$\begin{array}{c}3 \sigma \text { narrow tolerance } \\
\text { ranges }(50 \% \text { reduction })\end{array}$} \\
\hline & $\begin{array}{c}\text { Mean } \\
\text { stress } \\
{[\mathrm{MPa}]} \\
\end{array}$ & $\begin{array}{l}\text { St. dev. } \\
\text { [MPa] }\end{array}$ & $\begin{array}{c}\text { Prob. of } \\
\text { plastif. } \\
{[\%]}\end{array}$ & $\begin{array}{l}\text { Mean } \\
\text { stress } \\
{[\mathrm{MPa}]} \\
\end{array}$ & $\begin{array}{l}\text { St. dev. } \\
{[\mathrm{MPa}]}\end{array}$ & $\begin{array}{c}\text { Prob. of } \\
\text { plastif. } \\
{[\%]}\end{array}$ & $\begin{array}{l}\text { Mean } \\
\text { stress } \\
\text { [MPa] }\end{array}$ & $\begin{array}{l}\text { St. dev. } \\
{[\mathrm{MPa}]}\end{array}$ & $\begin{array}{c}\text { Prob. of } \\
\text { plastif. } \\
{[\%]}\end{array}$ \\
\hline $\begin{array}{l}\text { DI PS } \\
\text { Gr1 }\end{array}$ & 1112.8 & 56.3 & 100.000 & 1108.6 & 27.2 & 100.000 & 1109.1 & 27.3 & 100.000 \\
\hline $\begin{array}{l}\text { DI PS } \\
\text { Gr2 }\end{array}$ & 868.3 & 75.8 & 99.371 & 855.3 & 37.4 & 100.000 & 855.4 & 39.0 & 100.000 \\
\hline $\begin{array}{l}\text { DI PS } \\
\text { Gr3 }\end{array}$ & 641.5 & 33.0 & 12.771 & 646.7 & 16.2 & 2.314 & 647.0 & 16.6 & 2.704 \\
\hline $\begin{array}{l}\text { DI SS } \\
\text { Gr1 }\end{array}$ & 1162.0 & 53.2 & 100.000 & 1161.1 & 26.3 & 100.000 & 1159.7 & 25.7 & 100.000 \\
\hline $\begin{array}{l}\text { DI SS } \\
\text { Gr2 }\end{array}$ & 929.7 & 76.6 & 99.947 & 915.6 & 39.2 & 100.000 & 915.9 & 38.5 & 100.000 \\
\hline $\begin{array}{l}\text { DI SS } \\
\text { Gr3 }\end{array}$ & 723.6 & 33.9 & 90.567 & 726.6 & 17.4 & 99.695 & 726.0 & 16.1 & 99.827 \\
\hline
\end{tabular}

\section{CONCLUSIONS}

Dimensional tolerances significantly effect fir-tree locks of turbines while the probabilistic method provides much more information than the analysis of models with nominal or extreme dimensions. Bands of possible stress values are strictly dependent on the tolerance chain and tolerance ranges. Monte-Carlo simulations give a better view of construction and allow for more accurate prediction of potential problems even at an early stage of design, where the modification cost is much lower in comparison with later stages of the product life cycle.

The simulations show local plastifications in the grooves of the fir-tree locks which results in a reduction in fatigue life but is still acceptable by the Joint Aviaton Requirements [7]. Optimization of tolerance chains and better balancing of the blade airfoil would unify teeth loading and this way will reducing the maximum stress value and increasing the fatigue life of the whole turbine. 
A few improvement methods of fir-tree lock stress in a turbine have been presented: to narrow or shift tolerance ranges and reduction of scrapped parts (6-Sigma ideology). The latter one has an additional advantage of decreasing the number of blades rejected during further quality checks and measurements.

The next step would be considering probablilistic distributions of other parameters as well, such as: tolerances for other dimensions, temperature, pressure, material properties, etc. - standard deviations and expected ranges of peak stress values will increase. Avoiding of plastification in turbine blade locks is difficult from practical point of view. Therefore, it is necessary to apply additional solutions to reduce stress concentrations at the design phase of parts - for example shape optimization.

It is advised that researchers use parametric FE models coupled with 3-D scanning of real parts - analyses may be done for each of separately manufactured blade root disk groove pair to assess frequencies, stresses, low cycle fatigue life etc. The information allows for: a more accurate risk assessment of failure, an optimal order of blades in the disc (e.g. creating pairs with similar dimensions will lead to increasing and unifying fatigue lifetime of fir-tree locks in the whole turbine). This method does not require increasing of manufacturing accuracy or using more advanced technologies.

\section{REFERENCES}

[1] Arkhipov, A. N., Krasnovskiy, Y. E. and Putchkov, I. V. (2012). Probabilistic life assessment of turbine vanes. Proceedings of the ASME 2011 Turbo Expo: Turbine Technical Conference and Exposition. Volume 6: Structures and Dynamics, Parts $A$ and $B$. Vancouver, British Columbia, Canada. June 6-10, pp. 733-740. ASME. https://doi.org/10.1115/GT2011-45841.

[2] Folta, M. and Jachimowicz, J. (1995). Modelowanie w metodzie elementów skończonych tarcz wirników silników turbinowych. Przegląd Mechaniczny, 23/24, 13-18.

[3] Hall B. D. and Gray L. (2011). Probabilistic high-cycle fatigue risk assessment of an integrally bladed rotor. Proceedings of the ASME 2011 Turbo Expo: Turbine Technical Conference and Exposition. Volume 6: Structures and Dynamics, Parts $A$ and $B$. Vancouver, British Columbia, Canada. June 6-10, pp. 705-714. ASME. https://doi.org/10.1115/GT2011-45151.

[4] Jachimowicz, J., Kozłowski, P., Moneta, G., Szymczyk, E. and Kaniowski, J. (2010). Zjawisko frettingu w konstrukcjach lotniczych, Prace Instytutu Lotnictwa, 206, pp. 36-58.

[5] Jachimowicz J., Navrotski V. and Wawrzyniak A. (1997). Zastosowanie MES w analizach wytrzymałościowych wirników maszyn przepływowych. Przegląd Mechaniczny 71, pp. 10-14.

[6] Jachimowicz, J., Karliński, W. and Szachnowski, W. (2000). Blade and Disk In-Lock Co-Operation - Selected Problems. Machine Dynamics Problems, 24(4), pp. 71-86.

[7] Joint Aviation Requirements JAR-E Engines, Joint Aviation Committee, Change 9, 21 Oct 1994. 
[8] Klepacki W. (1975). Nieklasyczne zagadnienia drgań łopatek turbin lotniczych, PhD Disertation, Institute of Aviation, Warsaw.

[9] Moneta G., Jachimowicz J., Osiński J. (2014). Influence of Manufacturing Tolerances on Vibration Frequencies of Turbine Blade, Machine Dynamics Research, 38(1), 105-118.

[10] Peter, J. (1999). The History of Aircraft Gas Turbine Engine Development in the United States ... A Tradition of Excellence, Atlanta, Ga.: International Gas Turbine Institute of the American Society of Mechanical Engineers.

[11] Rolls-Royce plc. (1996). The jet engine, Derby, England.

[12] Wdowiński, W., Szymczyk, E., Jachimowicz, J. and Moneta, G. (2017). Design and Strength Analysis of Curved-Root Concept for Compressor Rotor Blade in Gas Turbine, Fatigue of Aircraft Structures, 2017, pp. 137-155, https://doi.org/10.1515/fas-2017-001. 